\title{
Shift-to-shift handoff: A comparison between two methods of conveying essential information in a University Hospital in North-eastern I taly
}

\author{
Rosanna Quattrin ${ }^{1}$, Laura Calligaris ${ }^{1}$, Carla Londero², Enrico Zalateu ${ }^{3}$, Silvio Brusaferro ${ }^{1}$ \\ 1. Department of Medical and Biological Sciences, University of Udine, Udine, Italy. 2. Azienda Ospedaliero-Universitaria \\ "Santa Maria della Misericordia”, Udine, Italy. 3. Hospital of Gorizia, Gorizia, Italy.
}

Correspondence: Rosanna Quattrin. Address: Department of Medical and Biological Sciences, University of Udine, Via Colugna, 5033100 Udine, Italy. E-mail: quattrin.rosanna@aoud.sanita.fvg.it

Received: January 6, 2014

DOI : $10.5430 /$ jha.v3n5p39
Accepted: April 4, 2014

Online Published: April 14, 2014

URL: http://dx.doi.org/10.5430/jha.v3n5p39

\section{Abstract}

Objective: The present study focuses on effective communication among nurses during a shift-to-shift handoff.

Methods: The completeness of data conveyed during the shift-to-shift handoff was compared in two University Hospital Units, before and after the introduction of a pre-printed sheet summarizing the most important patients' piece of information. The study took place in a University Hospital located in North-eastern Italy. In the first study phase 111 single patient's handoffs were analyzed: 52 in Operative Unit 1 (OU1) and 59 in Operative Unit 1 (OU2). In the second phase of the study 39 handoffs were considered: 19 in the OU1 and 20 in the OU2. The intervention consisted of the introduction of a pre-printed semi structured sheet summarizing the patients' information. The main outcome measures were the patients' information written on the form and the data available for consultation by colleagues on the next work shift.

Results: The four categories of items that most significantly increased after the introduction of the semi-structured form were respectively: neurological status, vital signs, pain assessment and wound care. However, none of the items that showed a reduction in citation, both for single OU and overall, were significant.

Conclusions: This study shows how the introduction of a pre-printed form forces the operators to hold in consideration important critical values of a patient, thus bettering the quality and safety of the handoffs.

\section{Key words}

Shift, Nurses, Communication, Patient safety

\section{I ntroduction}

There is a large body of research on communication in the health care setting. Professional communication practices or strategies and team collaboration have a relationship with improved patient outcomes and patient safety and there is strong evidence that improving communication also increases staff satisfaction ${ }^{[1,2]}$. 
To transfer essential information and responsibility for patient care from one health care provider to another is an integral component of communication in health care and it is known as a handoff ${ }^{[3-5]}$. An effective handoff supports transition of critical information and continuity of care and treatment. Clinical environments are dynamic and complex, presenting many challenges for effective communication. The literature highlights the effects of ineffective handoffs such as wrong patient's identification, wrong site surgery and, sometimes, patient death ${ }^{[6,7]}$. The communication methods impact on the effectiveness and efficiency of handoff as well as patient safety. Incomplete or missing information, for example about weight or allergies, can easily lead to medication errors.

The skills of the caregiver influence the handoff quality. Effective communication is timely, accurate, complete, unambiguous and understood by the recipient. A technique that seeks to overcome the variability among caregivers is the Situation, Background, Assessment and Recommendation (SBAR) briefing model that is being used successfully to enhance handoff communication ${ }^{[8,9]}$. In 2006 Joint Commission International (JCI) introduced a national patient safety goal to develop procedures for the handoff of patients between clinicians. The input came from the Sentinel Event Advisory Group on the basis of data collected in accredited hospitals which identified goals with the potential to protect patient safety ${ }^{[10]}$.

Hospitals should implement a standardized approach to handoff communication, including the ability to ask and respond to questions, the review of patient's data, treatment-plan updates and any change in the patient's condition. Interruptions during handoff should be limited to minimize the possibility that a piece of critical information would fail to be conveyed $^{[11]}$. Handoffs occur across the entire health care continuum: from one health care provider to another, from one location to another within the hospital, or between shifts in the same unit ${ }^{[12]}$.

The method of conveying information is also important. There are two possible ways of reporting information: verbal or written. A verbal report has the potential weakness of poor retention of information by the receiver, and there may be discrepancies between the reported status and the actual patient status because of memory failure on the part of the reporter ${ }^{[12]}$. It is better to write a concise up-to-date report as a support tool during handoffs. A good written report allows oncoming shift to review data ${ }^{[13]}$. Nevertheless, a poor shift report, with essential information not documented properly, may contribute to an adverse outcome. It is a challenge to develop a handoff process that is efficient, comprehensive, operatively feasible and based on objective descriptions of the patient's condition. For handover communication different tools or forms can be used. Different clinical scenarios require different handovers. Each handover must be designed to fit the workload and users need to be included in the design process. Some examples are on-line modules, discharge summaries, medication reconciliation forms, electronic discharge notifications ${ }^{[14]}$.

The present study focuses on effective communication among nurses during a shift-to-shift handoff.

\section{Methods}

The study took place in a University Hospital located in North-eastern Italy.

The completeness of data conveyed during the shift-to-shift handoff was compared in two University Hospital Units, before and after the introduction of a pre-printed sheet summarizing the most important pieces of patients' information.

Two surgical units took part in the pre-post interventional study: a general surgery unit (40 inpatient beds) and an orthopedic, maxillofacial and ophthalmological unit (40 inpatient beds). The study consisted of two phases. The researcher was a student nurse. In the first phase he was on afternoon shift, and used formal verbal-only or notes-based nursing handoff for five days in each Unit: general surgery, Operative Unit 1 (OU1) and specialist surgery Operative Unit 2 (OU2). The second phase took place after a month in the same two units. Between the two phases, a pre-printed semi structured format was designed and given to the chief nurses working in the two studied units. The legibility of the handwritten 
information, the use of abbreviations and the use of an international safety taxonomy were also part of the educational training pathway performed during the presentation of the form.

The grid used by the surveyor to collect information about the patient's condition conveyed in the two phases was a checklist including the items present in the semi structured form, i.e. the items of the SBAR model with some adaptations to fit the local context. The checklist was made up of 38 items divided into four categories (Situation, Background, Assessment, Recommendation), including all clinical information that should be conveyed, when pertinent, during the nursing handoffs to guarantee patient safety in the continuum of care. When a topic included in the checklist was mentioned during the handoff of a patient, the surveyor made a checkmark next to it, to prove that that aspect of the patient had been considered. The new checklist will be the topic of the next article.

In this study one form per patient's day had to be used as a semi structured nurse record and as a written up-to-date supporting report during the handoff. The sheet was divided into three columns, each corresponding to a shift change. It was made of a minimum data set of items that should always be in mind during shift-to-shift handoffs in order to guarantee patient safety. The pre-printed form consisted of some items that needed a yes or no response, some items needed to be filled in, and some others that were multiple choice. At the bottom of the form there was space left for writing any other information that had not been mentioned in the items before, but meant to be used for anything else the nurse believed to be important to be written that had not been recorded so far.

In the first phase of the study all inpatients' handoffs were observed in OU2, whereas in OU1 only those who belonged to one ward area (B section), since handoffs of the two ward areas (A and B section) take place at the same time in two different rooms. However, patients are distributed randomly between the two sections, to eliminate selection bias. In the second phase of the study a smaller number of patients were considered, due to the limited available time the nursing staff could dedicate to the study. In fact in this phase they had to fill in the pre printed form as well as their "old" nursing record, the official one that went into the patient's record.

The nursing staff were not selected in any way. It was only said that they would have been heard while doing the handoff. Those nurses whose shift started or ended at 14.00 hours local time that day were observed during the handoff. The chief nurse involved her staff in a review of the suggested form that was used during the second phase of the study, therefore the staff were aware of the aim of the study from the second phase on wards.

Data collected were processed using Microsoft Excel using a binomial code (0.1) to define whether a topic was mentioned or not during the handoff. The software SPSS (12.0 version) was used for statistical analysis. To test significance the non parametric Mann-Whitney test was used. $P$ values $<.05$ were considered as significant.

\section{Results}

In the first study phase 111 single patient's handoffs were analyzed: 52 in OU1 and 59 in OU2. In the second phase of the study 39 handoffs were considered: 19 in the OU1 and 20 the in OU2.

There was a global significant increase in quotation in the following items from before to after the intervention: neurological status, vital signs, pain, wound dressing characteristics, bowel, diuresis, psychosocial status, mobilization, central or peripheral venous catheter, diet/fast, vesical catheter, temperature, glycemic test, respiratory apparatus, radiology, oxygen therapy, dismissal and patient education.

The four categories of items that most significantly increased after the introduction of the semi structured form were: neurological status, vital signs, pain assessment and wound care. Note that none of the items that showed a reduction in citation, both for single OU and overall, were significant. 
The form was completed in by the nurses but they verbally conveyed only those items that they thought were the most relevant for each patient. Nevertheless information was written on the form and the data were available for consultation by the colleagues of the next work shift.

In the first phase of the study, the topics more frequently considered in the OU1 were respectively: diagnosis, drains and fluids/lines; and in the OU2 the most frequent items topics were: diagnosis, patient's history and out-of-range lab results. After the introduction of the semi structured form, in the second phase of the study, the most frequently quoted items in OU1 were: diagnosis, vital signs, oxygen therapy, and drains. In OU2 diagnosis, wound care and neurological status were the three most important items (see Table 1).

Table 1. Quotation of variables in the two phases of the study.

\begin{tabular}{|c|c|c|c|c|c|c|c|c|c|c|c|c|c|}
\hline & \multirow[t]{2}{*}{ VARIABLES* } & \multicolumn{2}{|c|}{$\begin{array}{l}\text { Phase I: } \\
\text { OU } 1 \text { (n. 52) }\end{array}$} & \multicolumn{2}{|c|}{$\begin{array}{l}\text { Phase I: } \\
\text { OU } 2 \text { (n. 59) }\end{array}$} & \multicolumn{2}{|c|}{$\begin{array}{l}\text { TOT Phase I } \\
\text { (n. 111) }\end{array}$} & \multicolumn{2}{|c|}{$\begin{array}{l}\text { Phase II: } \\
\text { OU } 1 \text { (n. 19) }\end{array}$} & \multicolumn{2}{|c|}{$\begin{array}{l}\text { Phase II: } \\
\text { OU } 2 \text { (n. 20) }\end{array}$} & \multicolumn{2}{|c|}{$\begin{array}{l}\text { TOT Phase } \\
\text { II (n.39) }\end{array}$} \\
\hline & & $\mathbf{N}^{\circ}$ & $\%$ & $\mathbf{N}^{\circ}$ & $\%$ & $\mathbf{N}^{\circ}$ & $\%$ & $\mathbf{N}^{\circ}$ & $\%$ & $\mathbf{N}^{\circ}$ & $\%$ & $\mathbf{N}^{\circ}$ & $\%$ \\
\hline Situation & Diagnosis & 31 & 59.6 & 59 & 100 & 90 & 81.1 & 15 & 78.9 & 20 & 100 & 35 & 89.7 \\
\hline \multirow{2}{*}{ Background } & Patient’s History & 0 & 0 & 25 & 42.4 & 25 & 22.5 & 0 & 0 & 10 & 50 & 10 & 25.6 \\
\hline & Allergies & 0 & 0 & 12 & 20.3 & 12 & 10.8 & 1 & 5.3 & 6 & 30.0 & 7 & 17.9 \\
\hline \multirow{14}{*}{ Assessment } & Temperature & 9 & 17.3 & 4 & 6.8 & 13 & 11.7 & 8 & 42.1 & 5 & 25.0 & 13 & 33.3 \\
\hline & $\begin{array}{l}\text { Neurologic } \\
\text { status }\end{array}$ & 9 & 17.3 & 7 & 11.9 & 16 & 14.4 & 8 & 42.1 & 14 & 70 & 22 & 56.4 \\
\hline & Oxygen therapy & 8 & 15.4 & 3 & 5.1 & 11 & 9.9 & 9 & 47.4 & 1 & 5.0 & 10 & 25.6 \\
\hline & Bowel & 9 & 17.3 & 4 & 6.8 & 13 & 11.7 & 5 & 26.3 & 13 & 65.0 & 18 & 46.2 \\
\hline & Diuresis & 11 & 21.2 & 12 & 20.3 & 23 & 20.7 & 8 & 42.1 & 11 & 55.0 & 19 & 48.7 \\
\hline & Vital signs & 9 & 17.3 & 17 & 28.8 & 26 & 23.4 & 13 & 68.4 & 12 & 60.0 & 25 & 64.1 \\
\hline & Pain & 2 & 3.8 & 12 & 20.3 & 14 & 12.6 & 7 & 36.8 & 13 & 65.0 & 20 & 51.3 \\
\hline & Glycemic test & 4 & 7.7 & 4 & 6.8 & 8 & 7.2 & 7 & 36.8 & 3 & 15.0 & 10 & 25.6 \\
\hline & Lab tests & 1 & 1.9 & 25 & 42.4 & 26 & 23.4 & 1 & 5.3 & 5 & 25.0 & 6 & 15.4 \\
\hline & Fluids/lines & 18 & 34.6 & 12 & 20.3 & 30 & 27.0 & 8 & 42.1 & 5 & 25.0 & 13 & 33.3 \\
\hline & Drains & 19 & 36.5 & 14 & 23.7 & 33 & 29.7 & 9 & 47.4 & 7 & 35.0 & 16 & 41.0 \\
\hline & CVC/PVC & 14 & 26.9 & 6 & 10.2 & 20 & 18.0 & 6 & 31.6 & 12 & 60.0 & 18 & 46.2 \\
\hline & Vesical catheter & 6 & 11.5 & 7 & 11.9 & 13 & 11.7 & 6 & 31.6 & 7 & 35.0 & 13 & 33.3 \\
\hline & Wound Dressing & 3 & 5.8 & 14 & 23.7 & 17 & 15.3 & 4 & 21.1 & 16 & 80.0 & 20 & 51.3 \\
\hline \multirow{3}{*}{$\begin{array}{l}\text { Recommen } \\
\text { dations }\end{array}$} & Consultancies & 10 & 19.2 & 15 & 25.4 & 25 & 22.5 & 6 & 31.6 & 6 & 30.0 & 12 & 30.8 \\
\hline & Tests/treatments & 12 & 23.1 & 20 & 33.9 & 32 & 28.8 & 1 & 5.3 & 7 & 35.0 & 8 & 20.5 \\
\hline & Diet/fast & 16 & 30.8 & 6 & 10.2 & 22 & 19.8 & 8 & 42.1 & 9 & 45.0 & 17 & 43.6 \\
\hline
\end{tabular}

* only those variables which total in either phase was $>5$ were included

The only variable that was cited in both units and in both phases more than half of the times was diagnosis: $81.1 \%$ in phase 1 and $89.7 \%$ in phase 2. No other variable was cited over 50\% in the first phase. On the contrary, in the second phase neurologic status, vital signs, pain and wound dressing were quoted more than half of the times. The variable "drains" was frequently cited in both phases respectively $29.7 \%$ in phase 1 and $41.0 \%$ in phase 2 . One other variable: "pain” went from $12.6 \%$ (phase 1) to $51.3 \%$ (phase 2), although one unit, the OU2, contributed mostly to this increase.

Overall the increase in variable quotation was seen on essential aspects of patient's assessment or care. Those variables that were not included in Table 1, i.e. those which were not quoted at least 5 times were: rest, respiratory apparatus, cardiac apparatus, central venous, dialysis, skin, mobilization, psychosocial status, radiology, enteral or parenteral probe, hydric balance, discharge plan, cultural mediation, patient education, caregiver identification, pressure sores, and falls. Table 2 illustrates the difference between the first and the second phase of the study in the two OUs. 
Table 2. Overall difference rate between the two units in the variables' quotation.

\begin{tabular}{|c|c|c|c|c|}
\hline & \multirow{2}{*}{ VARIABLES } & OU 1 & OU 2 & TOT. \\
\hline & & $\Delta \%$ & $\Delta \%$ & $\Delta \%$ \\
\hline Situation & Diagnosis & +19.3 & 0 & +8.6 \\
\hline \multirow{3}{*}{ Background } & Patient's History & 0 & +57.6 & +3.1 \\
\hline & Allergies & +5.3 & +6.7 & +7.1 \\
\hline & Rest & +8.6 & 0 & +4.2 \\
\hline \multirow{25}{*}{ Assessment } & Temperature & $+24.8^{*}$ & $+18.2^{*}$ & $+21.6^{*}$ \\
\hline & Neurologic status & $+24.8^{*}$ & $+58.1^{*}$ & $+42^{*}$ \\
\hline & Respiratory app. & $+10.5^{*}$ & $+15^{*}$ & $+12.8^{*}$ \\
\hline & Oxygen therapy & $+32.0^{*}$ & -0.1 & $+15.7^{*}$ \\
\hline & Cardiac app. & -5.8 & +3.4 & -4.5 \\
\hline & CV Pressure & +27.8 & 0 & +13.6 \\
\hline & Digestive app. & -1.9 & 0 & -0.9 \\
\hline & Bowel & +6 & $58.2^{*}$ & $+34.5^{*}$ \\
\hline & Diuresis & +20.9 & $+24.7^{*}$ & $+28.0^{*}$ \\
\hline & Dialysis & -1.9 & -1.7 & -1.8 \\
\hline & Mobilization & $+29.1^{*}$ & $+20.0^{*}$ & $+24.6^{*}$ \\
\hline & Skin & 0 & +1.7 & -0.9 \\
\hline & Psychosocial status & 0 & $+53.3^{*}$ & $+27.3^{*}$ \\
\hline & Vital signs & $+51.1^{*}$ & $+32.2^{*}$ & $+40.7^{*}$ \\
\hline & Pain & $+33^{*}$ & $+24.7^{*}$ & $+38.7^{*}$ \\
\hline & Glycemic test & $+29.1^{*}$ & +7.2 & $+18.4^{*}$ \\
\hline & Lab tests & +3.4 & -17.4 & -8 \\
\hline & Radiology & +1.8 & $+12.8^{*}$ & $+11.0^{*}$ \\
\hline & Fluids/lines & +7.5 & +4.7 & +6.3 \\
\hline & Drains & +11.2 & +1.3 & +11.3 \\
\hline & Parent/enteral probe & +12.6 & 0 & +5.8 \\
\hline & CVC/PVC & +4.7 & $+4.8^{*}$ & $+28.2^{*}$ \\
\hline & Vesical catheter & $+20.1^{*}$ & $+23.1^{*}$ & $+21.6^{*}$ \\
\hline & Hydric balance & +3.4 & -3.4 & -0.1 \\
\hline & Wound Dressing & +15.3 & $+54.6^{*}$ & $+36^{*}$ \\
\hline \multirow{9}{*}{ Recommendations } & Consultancies & +12.4 & +4.6 & +8.3 \\
\hline & Tests / treatments & -17.8 & +1.1 & -8.3 \\
\hline & Diet / fast & +11.3 & $+34.8^{*}$ & $+23.8^{*}$ \\
\hline & Dismissal & 0 & $+10.0^{*}$ & $+5.1^{*}$ \\
\hline & Cultural mediation & -1.9 & +1.6 & -0.1 \\
\hline & Patient Education & 0 & $+10.0^{*}$ & $+5.1^{*}$ \\
\hline & Caregiver & 0 & +5.0 & +2.6 \\
\hline & Pressure sores & 0 & -1.7 & -0.9 \\
\hline & Falls & 0 & 0 & 0 \\
\hline
\end{tabular}

${ }^{*} p<.05$

\section{Discussion}

The adoption of a semi structured handoff model showed a significant increase in the quality and quantity of information conveyed. Particularly relevant areas such as neurological status and vital signs had a significantly increase which may contribute to safer patient management. During the second phase of the study a significantly lower number of patients' handoffs was observed, since the filling in of the semi structured form was an additional workload for the nursing staff who agreed to use this new kind of handoff only for a limited number of cases (being an experimental study this form was 
not inserted in the patient's record and the nurses had to write the patient's information twice, once in the new form and a second time in the nurse record).

In the first phase of the study patient's name and his bed number were used for identification before any diagnostic or performing procedures. This type of identification is not included in the first international safety goal of JCI that requires at least two ways in which to identify a patient ${ }^{[11]}$. Therefore the new form contemplates a white space where a sticker with the patient's birth date and his medical record number. These two different identifiers are utilized in all locations within the hospital.

Some variables such as falls have not been quoted in either phase and this could be explained by the fact that there isn't any formal fall protocol in use in this hospital, although it is about to be introduced. The nurses have not been trained about it yet. The variable "diagnosis" had no room for improvement in the OU2 because it was $100 \%$ compliant already in the first phase. On the contrary, the same item in the OU1 had never been quoted, maybe because the mean length of stay of the patient in this unit is longer and the nurses take it for granted.

Since in the second phase of the study the patient's values or information were written down and the nurse performing the handoff obtained information on his/her own, he/she verbally quoted them more frequently maybe because he/she thought that they were important for the safety of the patient. In this perspective keeping all patient's relevant data on one sheet of paper can help to save time.

It must be highlighted that the increase in quotation in both operative units deals with issues of paramount importance and this supports the validity of the pre-printed form.

The assessment of the patient's skin in relation to the pressure sores risk was not often quoted and this could be explained by the fact that patients considered were autonomous for most of the time during their hospital stay and therefore did not have kind of problem.

The "pain assessment" has been significantly increasing in both units. A tool like a pre-printed form including this item stimulates the nurses to assess the pain in all patients and not only those who complained of the symptom. A widespread assessment of the pain in all inpatients, and an efficacious therapy is also a strong quality marker for the hospital.

Data about "out of range lab values" are more frequently mentioned in the OU2 because this unit also admits orthopedic patients who have hip replacement interventions, and need routine assessment of hemoglobin values to have blood transfusions of pre deposited blood in ward after the intervention.

The "wound dressing" was a neglect item in the first phase but it was considered more frequently in the second phase. The assessment and the daily written description of the wound dressing, even if it is clean and dry, is of paramount importance to timely detection of any changes in its status and subsequent treatment as soon as any surgical site infection is detected

"Patient education" and "identification of the caregiver" are two variables that need to be implemented as well.

Issues that overall were seen to be significantly increased were: the neurological status, the vital signs, the pain assessment and the surgical site status. The assessment of these aspects, very important for the patient's condition or comfort, demonstrates that "structure drives behavior" and that a written support during handoff is not just another form to fill in but it has essential quality implications. Those items that were not frequently quoted could also not apply to that patient, even if important by themselves when pertinent (dyalisis, glycemic test, cardiac apparatus failures, etc.)

This study has also a few limitations. The sample of patients, especially in the second phase of the study, was small and the sample is made of surgical patients only. But since it was an innovative handoff method in our hospital, we preferred to start with two similar areas and with a smaller group of patients to test the appropriateness of the form. One could object 
that the difference in item quotation could be the result of different case mixes between the two phases of the study, but we think that this is not the case since the two OUs chosen perform only elective surgery and the type of patients doesn't change over time. We did not differentiate between patients who underwent a surgical procedure and patients that did not. This might have influenced the percentage of patients with variables related to drains and wound dressing but we suppose that they were equally distributed among the two phases in the two OUs. There is finally no bias linked to the researcher, because one single person performed all the observations by himself.

In the healthcare setting communication is extremely important and also the way information is conveyed plays its part, especially if we consider that this aspect is often left behind in the hierarchy of values of the healthcare personnel. Good communication skills and, above all, pre defined evidence based contents during handoffs mean good quality of care.

A structured pre-printed form, a new method for collecting and recalling data during the shift-to-shift handoff was chosen because it had already been shown in literature to be the most effective ${ }^{[13,15,16]}$. This method is supported by studies that encourage the use of a consistent pre-printed forms with relevant patient information during shift report, with less reliance on verbal-only reports, in order to optimize communication. A study by Pothier and collegues ${ }^{[17]}$ examined three different methods of handoff for transferring information during five consecutives simulated handoffs of 12 fictional patients. Three methods of handoffs were analyzed; the method demonstrating the greatest amount of information retention involved utilization of a pre-printed sheet containing patient information with verbal report (96\%-100\%), followed by note taking and verbal report method (31\%-58\%), and lastly, only verbal report (0-58\%). The insertion of incorrect information was observed in the verbal-only method.

As far as the content of the form is considered, the SBAR model was appreciated by the staff, because it was clear and exhaustive. Its frame considers respectively: the Situation (the problem), the Background (brief history and relevant context), the Assessment (what you think is going on), and the Recommendation (what you want, what needs to be fixed).

The introduction of a new form implied resistance in changing behaviors by some nurses though the majority accepted its. In fact personnel education about reasons to introduce this kind of innovation, particularly the patient's safety, determined a high level of agreement.

This project is a part of a wider approach to continuous quality improvement adopted by the entire hospital that includes other safety goals. The target of this study is the nursing staff but the challenge is to spread tools that help the handoffs to the medical staff in the future. This study focalizes on nurse's handoff also because a new format of nurse record is being reviewed at this time.

Education and training in the safety issues mean improvement in professional quality, where quality is a feature of the daily work and communication plays a predominant role.

\section{Conclusions}

This study shows how the introduction of a pre-printed form forces the care givers to take into consideration important critical values of a patient's record, thus bettering the quality and safety of the handoffs.

The four items categories that most significantly increased after the introduction of the semi structured form were respectively: neurological status, vital signs, pain assessment, wound care. None of the items that showed a reduction in citation, both for single OU and overall, were significant. The pre-printed form is a versatile tool. It is modifiable on the basis of the context, but a minimum set of information has to be included in it to guarantee patient's safety. Moreover, the educational programs during the introduction of the form and the sharing of information/variables/items in the form with the nursing staff resulted in the high acceptance of the new handoff method. It is recommended that this new tool is adopted hospital-wide in the near future.

Published by Sciedu Press 


\section{References}

[1] Boyle DK, Kochinda C. Enhancing collaborative communication of nurse and physician leadership in two intensive care units. J Nurs Adm. 2004; 34: 60-70. http://dx.doi.org/10.1097/00005110-200402000-00003

[2] Smith AP. Partners at the bedside: the importance of nurse-physician relationships. Nurs Econ. 2004; 22: 161-4. PMid: 15211923.

[3] Australian Council for Safety and Quality in Health Care. Clinical Handover and patient safety literature review report. 2005; Available from: http://www.safetyandquality.org/index.cfm?page=Publications\#clinhovrlit

[4] Ong MS, Coiera E. A systematic review of failures in handoff communication during intra hospital transfers. Jt Comm J Qual Patient Saf. 2011; 37(6): 274-284. PMid: 21706987.

[5] Solet D, Norvell JM, Rutan GH, et al. Lost in translation: challenges and opportunities in physician to physician communication during patient handhoffs. Acad Med. 2005; 80: 1094-99. PMid: 16306279. http://dx.doi.org/10.1097/00001888-200512000-00005

[6] Gandhi TK. Fumbled handoffs: one dropped ball after another. Ann Intern Med. 2005; 142: 352-358. PMid: 15738454. http://dx.doi.org/10.7326/0003-4819-142-5-200503010-00010

[7] Rabøl LI, Lehmann Andersen M, Østergaard D, et al. Descriptions of verbal communication errors between staff. An analysis of 84 root cause analysis-reports from Danish hospitals. BMJ Qual Saf. 2011; 20(3): 268-274. PMid: 21209139. http://dx.doi.org/10.1136/bmjqs.2010.040238

[8] Leonard M, Graham S, Bonacum D. The human factor: the critical importance of effective teamwork and communication in providing safe care. Qual Saf Health Care. 2004; 13(suppl 1): i85-i90. PMid: 15465961. http://dx.doi.org/10.1136/qshc.2004.010033

[9] Haigh KM, Sutton S, Whittington J. National Patient Safety Goals. SBAR: a shared mental model for improving communication between clinicians. Jt Comm J Qual Patient Saf. 2006; 32: 167-175. Available from: http://www.jointcommission.org/about_us/who_we_are.aspx

[10] Joint Commission International. Joint Commission International Standards for Hospitals. 5rd ed. Oakbrook Terrace, USA. 2014.

[11] Hughes RG. Patient safety and quality: an evidence-based handbook for nurses. AHRQ Publication no. 08-0043. Rockville, MD: Agency for Healthcare Research and Quality, March 2008.

[12] Kennedy J. An evaluation of non-verbal handover. Prof Nurse. 1999; 14: 391-394. PMid: 10205535.

[13] Philibert I, Barach P. The European HANDOVER Project: a multi-nation program to improve transitions at the primary care-inpatient interface. BMJ Qual Saf. 2012; 21: i1-i6. PMid: 23173180. http://dx.doi.org/10.1136/bmjqs-2012-001598

[14] Institute for Healthcare Improvement. Shifting to a higher standard. 2005. Available from: http://www.ihi.org/IHI/Topics/MedicalSurgicalCare/MedicalSurgicalCareGeneral/ImprovementStories/ShiftingtoaHigherStandar d.htm.

[15] Strople B, Ottani P. Can technology improve intershift report? What the research reveals. J Prof Nurs. 2006; 22: 197-204. PMid: 16759963. http://dx.doi.org/10.1016/j.profnurs.2006.03.007

[16] Bhabra G, Mackeith S, Monteiro P, et al. An experimental comparison of handover methods. Ann R Coll Surg Engl. 2007; 89: 298-3000. PMid: 17394718. http://dx.doi.org/10.1308/003588407X168352

[17] Pothier D, Monteiro P, Mooktiar M, et al. Pilot study to show the loss of important data in nursing handover. Br J Nurs. 2005; 14: 1090-1093. PMid: 16301940. 